\title{
A Study Of HRM's Response To The Events Of 9/11
}

James H. Browne, (E-mail: browne@uscolo.edu), University of Southern Colorado Stuart H. Warnock, (E-mail: warnock@tarleton.edu), Tarleton State University Nancy J. Boykin, (E-mail: boykin@ tarleton.edu), Tarleton State University

\begin{abstract}
The 9/11 terrorist attacks leveled the twin towers of New York's World Trade Center, caused serious damage to the Pentagon, and disrupted the national economy. The response by corporate organizations, hardest hit by the events of 9/11, has turned the familiar phrase "business as usual" into an anachronism. Effective human resource management (HRM) practices are critical for any organization to appropriately respond and recover from catastrophic events, such as those of 9/11. In the aftermath of 9/11, corporate organizations have recognized the need to change many of their HRM practices. Possible explanations for recent changes in HRM practices are twofold: 1) as precautionary measures intended to avert man-made disasters, and 2) to enhance the organization's capability to immediately and effectively respond should a disaster strike. Irrespective of the reasons organizations are changing their HRM practices, they are placing more importance than ever on the need to optimally utilize and safeguard their most valued asset - employees. Exploratory research on the initial responses by corporate organizations to the events of 9/11 reveals: 1) that many did not have disaster plans in place, and 2) that an even larger number were poorly prepared to deal with the disaster's immediate impact on employees, particularly the negative psychological consequences engendered by such a disaster. This exploratory paper culminates in a proposed HRM Practices Disaster Recovery Diagnostic Tool. This tool would allow an organization to assess the adequacy of their HRM practices in responding to man-made disasters.
\end{abstract}

\section{Introduction}

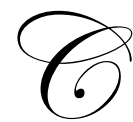

orporate organizations recognize the strategic importance of having contingency plans in the event of an economic crisis, natural disaster, or a man-made disaster (Phelps, 1986; Bradford, 2001). These types of contingency plans are referred to by a variety of names including emergency preparedness plans, critical incident response plans, business recovery plans, and disaster plans. Given the recent events on $9 / 11$, the scope of this paper will be limited to a specific type of contingency planning by a corporate organization; i.e., disaster planning. The importance of having an effective disaster plan is straightforward; it can make the difference between survival and death, in both human lives and for the organization itself (Taylor, 1995; Steffer, 1998). In light of the widely recognized need for organizations to have disaster plans, it is questionable whether most organizations had adequately planned for the severity of the economic and operational consequences following the events of $9 / 11$.

The immediate impact from the 9/11 Attack on America was unprecedented in US history as evidenced by the total shutdown of all US commercial air traffic for several days. The events of 9/11 cost the US airline industry an estimated $\$ 5$ billion and resulted in cutbacks of more than 100,000 employees (Snow, Karl, and Garrett, 2001). The International Air Transport Industry Association reports that the overall loss to the world's airlines may total $\$ 15$ billion from substantial reductions in passenger and freight services (Nullis, 2002). In addition to the airline industry, many other industrial sectors have been also been hard hit. A recent study by the Milken Institute predicts that $9 / 11$

Readers with comments or questions are encouraged to contact the authors via email. 
will result in US job losses of more than 1.6 million in a wide range of industries from tourism and dining to financial services (Avery, 2002). Without question, corporate organizations and the nation itself have been deeply effected by these events.

In addition to the loss of life, revenue, and jobs, the short-term financial impact from 9/11 can be assessed by examining insured losses. These losses are expected to be double those from either the 1994 Northridge, California earthquake or the 1992 devastation experienced in the southeastern US from Hurricane Andrew (Bates, 2001). While the long-term impact from 9/11 on the nation's economy is unknown, there are many indications that the economic fallout will be staggering (Shea, 2001).

In the aftermath of these attacks, many of the nation's employers have taken actions that will change the manner in which they manage their human resources (Thompson, 2001). A strong argument can be made that foremost among these actions is the need for organizations to take precautionary measures to avoid or minimize the occurrence of manmade disasters. The old adage "an ounce of prevention is worth a pound of cure" rings truer than ever. Even the best preventative efforts cannot guarantee that another man-made disaster, such as that of $9 / 11$, will not occur at some future time. Should the unthinkable happen, it is imperative that organizations have disaster plans in place, plans that include effective HRM practices allowing for an immediate and appropriate response. Prior to $9 / 11$, effective HRM practices were recognized as having strategic importance to the success of corporate organizations in a global economy characterized by uncertain economic conditions and heightened international political tension (Schuler and Jackson, 1999; Lado, 2000). Subsequent to $9 / 11$, HRM practices have certainly increased in their strategic importance to corporate organizations.

\section{Problem, Purpose, and Significance of the Study}

The tragic events of 9/11 have depressed an already sluggish US economy. To paraphrase President George W. Bush, "the nation is fighting a new kind of war in its efforts to rid the world of terrorism. The war that will be fought on many fronts and it may take years before victory is achieved." One of the fronts on which this "new war" will be fought is corporate America. It is imperative that organizations learn from 9/11 and assess the adequacy of their HRM practices in effectively responding to 9/11-type disasters. Therefore, this paper proposes a diagnostic tool by which organizations can assess the adequacy of their current HRM practices, and identify needed changes in their practices.

\section{Relevant Literature}

There is a small but growing body of literature addressing the impact of the 9/11 on HRM practices. One study, titled HR Implications of the Attack on America, described how corporate organizations responded to 9/11 and predicted subsequent changes in HRM practices in the workplace (eePulse and the Society for Human Resource Management, 2001). Data for this study was collected from $9 / 18 / 01$ to $9 / 21 / 01$ using an online survey comprised of eight closed-ended and two open-ended questions. Of the 120,000 HRM professionals to whom the survey's URL was e-mailed, 5,673 completed the online questionnaire. It is important to note that professionals working in all five HRM functional areas (i.e., recruitment, compensation, health and safety, training and development, and employee and labor relations) responded to the survey. Analysis of the respondents' answers show that $46 \%$ did not have disaster plans in place, and that $60 \%$ were poorly prepared to deal with the disaster's aftermath. In addition, this study predicted changes in HRM practices as follows:

1. Disaster planning - new disaster plans will be written and existing plans will be updated or expanded.

2. Orientation - greater emphasis will be placed on disseminating these plans in new employee orientation.

3. Security/safety - greater emphasis on security, higher security provisions, and issues of workplace violence.

4. Recruitment - increased screening of employees.

5. Employee relations - greater attention to employee relations' issues.

6. Diversity initiatives - the fastest growing religion in the world is the Islamic religion and this is reflected in the American workplace.

7. Training and development - placing more emphasis on security, recruitment, employee relations, and diversity initiatives will be translated into training and development activities, greater training for how to deal with a disas- 
ter and the counseling and psychological needs that result.

Sullivan (2001) suggests that in addition to injury and death, numerous employee-related problems are created by traumatic events (e.g., fear, anxiety, harassment, and decreased productivity) and proposes HRM practices that address these types of problems. The HRM practices suggested for responding to a 9/11-type disaster include:

1. Training managers in techniques for addressing employee anxiety and concerns;

2. Being more flexible in administering policies for sick leave, vacations, telephone use at work, telecommuting, and rescheduling or canceling business trips on commercial flights;

3. Designating an HR person to be the primary contact for issues related to the event;

4. Providing needed employee counseling via telephone, onsite, and/or through the organization's EAP vendor;

5. Contacting expatriates at risk for terrorism/retaliation, asking what they need, and responding quickly to their needs;

6. Enlisting employees in reporting harassment immediately and identifying employees "at risk" for violence or harassment;

7. $\quad$ Keeping employees informed about news events through e-mails, Website, etc.;

8. Offering immediate financial and counseling support to the families of injured/dead employees;

9. Reviewing and upgrade the organization's disaster plan.

Heathfield (2002) identified several trends that are occurring world-wide in the HRM practices of corporate organizations as a result of $9 / 11$. The trends include:

1. Increased use of electronic communication for meetings (e.g., video conferencing Web conferencing, email, mailing lists, in-house or Intranet discussion boards and cell phones) reduces the need for business travel;

2. Increased use of information technology for training (e.g., online instruction, use of a CD for training, and virtual universities);

3. Greater emphasis on employee safety and company security (e.g., requiring employees to use access cards and only one entrance is open, visitors are signed in by a security guard, etc.);

4. Requiring background checks on potential employees during the recruiting process;

5. Enhancing employee relations via company organized community service projects that bring employees together (e.g., donation drives, fund-raising events and activities, provided time to donate blood, and workplace potlucks to bring employees closer together).

The above review highlights responses by corporate organizations to $9 / 11$ vis-à-vis changes in a variety of HRM practices. A dominant and recurrent theme concerns the critical need for organizations to have an effective disaster plan. A successful disaster plan will enable the organization to immediately respond to a disaster by taking the requisite action to survive the disaster and resume critical business operations as quickly as possible. In light of the fact that almost half of corporate organizations did not have a disaster plan in place on 9/11, the disaster planning-related HRM practices that help an organization survive and recover from a disaster need to be identified. A generic "project plan outline" that details the steps for developing a disaster recovery plan was reviewed (CMS-UT, 2002). This review showed that the HRM practices required for effective disaster recovery planning include:

1. Developing HRM policies that support the disaster recovery plan to provide for the safety and well being of people on the premises;

2. Conducting a security assessment of personnel practices and the HRIS database;

3. Management succession planning;

4. Job analysis to establish and documenting the roles and responsibilities of the recovery team members;

5. $\quad$ Training staff with recovery responsibilities to execute their portion of the plan;

6. Program evaluation when testing the plan's ability to meet established recovery standards.

HRM practice has changed as a result of the 9/11 tragedy. In many instances, good can be come from bad, and a particularly noteworthy change post-9/11 is the heightened sense of awareness concerning the importance of disaster plan- 
ning and HRM's role in that process. HRM's contribution to the disaster planning process has been noted, highlighting those practice areas where HRM can contribute. These authors would suggest, however, that a necessary yet overlooked precursor to undertaking any systematic disaster planning process is the process of self-discovery or assessment. Via such a self-assessment and accompanying diagnosis, the disaster planning process itself can be tailored to better insure its relevance and effectiveness. The paper now turns to the development of just such an evaluation instrument.

\section{Methodology}

Several activities are required to develop and validate any diagnostic tool. This study will propose an HRM Practices Disaster Recovery Diagnostic Tool and propose the methodology for its validation. The proposed HRM Practices Disaster Recovery Diagnostic Tool was constructed based on a review of the HRM functions and function-related activities as reported by BNA in its 2000-2001 survey of HRM activities, budgets, and staffs (BNA, 2001).

Survey items were written to correspond to each area in the BNA survey and are presented below. The survey items were written using the following five-point category scale.

\begin{tabular}{|c|c|c|c|c|}
\hline 1 & 2 & 3 & 4 & 5 \\
Not At All & To a Limited Extent & To a Modest Extent & Fairly Extensively & Very Extensively \\
\hline
\end{tabular}

Consider the overall disaster planning process used by your firm.

1. My organization has a disaster recovery plan in place.

2. The HRM staff was involved throughout the disaster recovery planning process.

A disaster could result in denial of access to critical HRM functions and services required for establishing normal business operations.

3. Critical HRM functions and services were identified during the disaster recovery planning process.

4. The economic impact resulting from the denial of critical HRM functions and services in times of disaster has been identified.

5. The timeframes in which critical HRM functions and services must be recovered after interruption have been identified.

6. An HRM recovery requirement profile has been developed for computer hardware.

7. An HRM recovery requirement profile has been developed for computer software.

8. An HRM recovery requirement profile has been developed for software documentation.

9. An HRM recovery requirement profile has been developed for outside support (e.g., data processing services).

10. An HRM recovery requirement profile has been developed for facilities (e.g., office space, and equipment).

11. An HRM recovery requirement profile has been developed for key HRM personnel.

Consider the role of HRM professionals in the disaster planning process.

12. There is/are HRM professional(s) dedicated as a resource person for disaster recovery planning.

13. HRM staff has had an active role in the continuous testing and exercising of disaster recovery plans.

14. HRM personnel are dedicated to the on-going maintenance of the disaster recovery plan.

15. HRM's review and updating of the disaster recovery plan occurs regularly to reflect changes in information processing and business environments.

16. HRM is represented on the Disaster Recovery Plan's Steering Committee.

Now consider the interface of various HRM areas with the disaster plan. 
17. HRM policies that support the disaster recovery plan provide for the safety and well being of people on the premises.

18. There has been a security assessment of HRM personnel practices.

19. There has been a security assessment of the HRIS database.

20. There is a formal management succession plan.

21. HRM has conducted a job analysis to establish and document the roles and responsibilities of the recovery team members.

22. HRM plays a role in training staff with recovery responsibilities to execute their portion of the plan.

23. HRM has been involved in program evaluation when testing the plan's ability to meet established recovery standards.

24. Training workshops targeting all employees (managerial and non-managerial) have been conducted to educate staff about the potential range of the emotional impact of a disaster.

25. There has been preliminary training for primary and contingency/back up staff in the area of internal response protocols.

26. There has been a selection of an external vendor (perhaps the organization's current EAP provider) who can offer comprehensive critical incident stress/trauma debriefing services immediately after a disaster.

27. There has been training, via role-play, to test the disaster plan.

28. There is increased use of electronic communication for meetings (e.g., video conferencing Web conferencing, email, mailing lists, in-house or Intranet discussion boards and cell phones) that reduces the need for business travel.

29. There is increased use of information technology for training (e.g., online instruction, use of a CD for training, and virtual universities) related to the disaster plan.

30. There is greater emphasis on employee safety and company security (e.g., requiring employees to use access cards, only one entrance open, visitors are signed in by a security guard, etc.).

31. Background checks are required on potential employees during the recruiting process.

32. There is an orientation program that places great emphasis on disseminating the disaster recovery plan to new employees.

33. There is greater emphasis being placed on security and issues of workplace violence.

34. There is greater emphasis on employee relations' issues such as diversity initiatives.

35. There has been training for supervisory personnel on how to deal with a disaster's aftermath regarding the counseling and psychological needs of employees.

36. Flexible work practices (e.g., telecommuting and outsourcing) have been planned for in the event of a disaster.

The thirty-six item questionnaire has been reviewed by an expert panel of three HRM faculty to check for clarity, relevance, and completeness. A pretest will be conducted involving ten HRM practitioners selected on a convenience basis. The HRM practitioners will review the questionnaire to detect items that are unclear or otherwise confusing. Incorporating the insights of the pretest, the questionnaire will be finalized in the form of a mail survey instrument. In addition to the questionnaire items above, demographic items concerning respondent age, gender, experience, HRM functional responsibilities, and firm size and industry classification will be included.

The mail survey will be sent to 500 HRM professionals that are members of SHRM. A dual-stage cluster sampling procedure will be utilized wherein twenty-five SHRM chapters will be randomly selected across the U.S. At the second stage, twenty HRM professionals will be randomly selected from each cluster/chapter. Dillman's (1978) Total Design Method will be employed with a total of four waves of surveys being sent.

Once data are collected, scale purification will proceed. The survey consists of multiple items related to the categories of HRM's involvement in the disaster planning process, adequacy of plans for interruption of key services, and the interface of each HRM functional area with the disaster planning process. The multiple items corresponding to each category will be summed to arrive at a summated scale, then scale reliabilities will be computed and items will be deleted to enhance scale reliability. Nunnaly's (1978) Item-Scale analysis will then be conducted to assess the assignment of items to scales. Items will be reassigned or deleted from scales based on these findings. 
Finally, descriptive statistics will be computed for each of the validated scales. The descriptive statistics will be broken out by industry for purposes of providing norming data.

\section{Conclusions}

The tragic events of $9 / 11$ have provided the impetus for corporate organizations to take pause and consider the enormous implications of this event on their future. HRM practice has changed as a result and there is an increasing awareness of the inadequacy of the disaster planning process in most organizations. HRM professionals should play a key role in redefining and improving the disaster planning process in their organizations.

The first step in any such undertaking is to step back before moving forward. An assessment of where the organization currently stands vis-à-vis disaster planning is important to better inform and guide future disaster planning efforts. This study has presented an assessment tool designed to facilitate this self-discovery process. Methodology for validating this diagnostic tool has been presented and is ongoing. This tool will be a valuable contribution to HRM professionals taking stock of where their organizations are at and will provide a point of comparison relative to other corporate organizations as well.

\section{References}

1. Avery, Simon (2002). "More Americans will lose jobs in 2002, study predicts." Special Report by AP Online. January 11. http://www.nando.net/special_reports/terrorism/economics/story/216744p2089522c.html.

2. $\quad$ Bates, Steve (2001). "Insurers set to process billions in claims." HR News, November: Vol. 20, No. 11, 5.

3. BNA, Inc. (2001). "SHRM-BNA Survey No. 66: Human resource activities, budgets, and staffs." Bulletin to Management: Workplace Policy and Practice Insights Since 1950, June: Vol. 52, No. 26, Part 2, (S1-S42).

4. Bradford, Michael (2001). "Attacks put focus on crisis plans.” Business Insurance, Vol. 35, No. 39 (Sept. 24), 3 and 18.

5. CNS-UT (2002). "Disaster Recovery Planning." Published on the University of Toronto's Website by Computer Networking Services. http://www.utoronto.ca/security/drp.htm.

6. Dillman, Don A. (1978) Mail and Telephone Surveys: The Total Design Method, New York: John Wiley \& Sons.

7. eePulse and the Society for Human Resource Management (2001). "HR Implications of the Attack on America." http://www.shrm.org/surveys/results/finaltoal.pdf.

8. Heathfield, Susan M. (2002). "What Organizations Are Talking About in the Aftermath of the September 11th Atrocity: Part 2." HR Community Connection Newsletter, March 14.

http://humanresources.about.com/library/weekly/aa100601b.htm.

9. Lado, Augustine (2000). "Strategic Human Resource Management Reviewed." The Academy of Management Review, July: No. 3, 677-679.

10. Masie, Elliot (2001). "Training Reactions to Terrorist Attacks: How have organizations adjusted learning and collaboration in response to the terrorist attacks?" The Massie Center: Research and Reports. http://www.masie.com/masie/researchreports/09-20-2001-survey/webpage.htm?page=researchreports/09-202001-survey/webpage.htm.

11. McCoy, David (2001). "Aftermath: Disaster Planning and Business Recovery." Gartner Research, September 21. http://www3.gartner.com/1_researchanalysis/focus/aftermath.html.

12. Nullis, Clare (2002). "Losses for airline industry may total $\$ 15$ billion." AP Online, February 5. http://www.nando.net/special_reports/terrorism/economics/story/240616p-2289215c.html

13. Nunnally, J.C. (1978) Psychometric Theory, New York: McGraw-Hill

14. Phelps, Norman (1986). "Setting up a crisis recovery plan." Journal; of Business Strategy, Vol. 6, No. 4., (Spring), $5-10$.

15. Schuler, Randall S. and Jackson, Susan E. (ed.) (1999). Strategic Human Resource Management. Oxford: Blackwell.

16. Scott, Donna and Glassman, Bill (2001). “The Ripple Effect: Disaster's Indirect Impact.” Gartner Research, September 20. http://www3.gartner.com/1_researchanalysis/focus/aftermath_atv1.html 
17. Shea, Terence F. (2001). "US economy was rocked, but not knocked out." HR News, November: Vol. 20, No. 11,1 and 9.

18. Snow, Kate; Karl, Jonathon; and Garrett, Major (2001). "White House, Congress nearing agreement on airline bailout." CNN.com/Travel, September 18. http://www.cnn.com/2001/TRAVEL/NEWS/09/18/rec.mineta.airlines

19. Steffer, Kristina (1998). "Critical Incident Response Planning." A White Paper published on the Web site of The Society for Human Resource Management. http://www.shrm.org/whitepapers/documents/default.asp?page=61857.asp

20. Sullivan, John (2001). "How Should HR and Managers React in the Aftermath of Terrorism Events?" Electronic Recruiting Exchange Daily, September 12.

http://www.erexchange.com/articles/default.asp?d=H\&CID=\{0CCBE40B-872D-47E7-BF4320FFA0ACA05E

21. Taylor, Suzanne (1995). "Disaster - Emergency Preparedness." A White Paper published on the Website of The Society for Human Resource Management. http://www.shrm.org/whitepapers/documents/default.asp?page=61855.asp

22. Thompson, Robert W. (2001). "Workplace attack risk can be reduced, not eliminated." HR News, November: Vol. 20, No. 11, 2, 4-5.

23. Wheatman, Vic (2001). "Aftermath: Disaster Recovery." A Special Report published on the Website of Gartner, Inc. http://www3.gartner.com/1_researchanalysis/focus/aftermath_atv1.html

24. Wheatman, Vic; Scott, Donna; and Witty, Roberta (2001). "Aftermath: Business Continuity Planning." A Special Report published on the Website of Gartner, Inc. http://www3.gartner.com/DisplayDocument?doc_cd=101098

Notes

Notes 
